\title{
A COMPARATIVE LOOK ON THE DROPPING OUT OF ADOLESCENTS IN SITUATIONS OF RISK FROM THE BEDOUIN EDUCATIONAL SYSTEM IN THE NEGEV
}

\begin{abstract}
Abu Ajaj Ibraheem, A Comparative Look on the Dropping out of Adolescents in Situations of Risk from the Bedouin Educational System in the Negev [Perspektywa porównawcza rezygnacji ze szkoły $\mathrm{w}$ sytuacjach ryzyka nastoletnich uczniów w beduińskim systemie oświaty w regionie Negew]. Studia Edukacyjne nr 40, 2016, Poznań 2016, pp. 283-303. Adam Mickiewicz University Press. ISSN 1233-6688. DOI: $10.14746 /$ se.2016.40.16
\end{abstract}

The phenomenon of dropping out of students from the educational system in Israel has been steadily increasing in recent years. Many research studies that addressed the phenomenon of dropping out indicated an increase in the percentage of students dropping out from the Bedouin educational system in the Negev.

The present research study examines the tendency to drop out of adolescents in situations of risk in the recognized Bedouin communities in comparison to adolescents in situations of risk in the unrecognized Bedouin communities with regard to different demographic variables and the involvement of the parents. These adolescents are daily exposed to emotional and social difficulties and do not receive adequate research attention. The issue of the dropping out of adolescents is an acute problem with considerable significance in the Arab sector in general and in the Bedouin communities in particular. The research study examines the situation today, the situation of the adolescents who are dropping out, their problems, and the reasons that led them to dropping out, in a comparison between the two types of Bedouin communities. The research findings will indicate possible ways for the reduction of the multidimensional phenomenon of dropping out.

In light of the large gaps that exist between the educational system in Jewish society and the educational system in Bedouin society, the research study emphasizes that there is a direct impact on the Bedouin educational system, which directly influences the dropping out of students from the educational system in general and the dropping out of students in situations of risk.

The sample consisted of 90 adolescents in situations of risk, 45 adolescents from recognized communities and 45 adolescents from unrecognized communities from different schools. In light of the examination of the research findings, it appears that the involvement of the parents influences the drooping out significantly. This finding indicates the importance of parental involvement in the school and its importance for the future of the children. In other words, a Bedouin child with an involved family will likely remain in the educational framework, while a Bedouin child whose parents are disconnected from his studies has increased chances to drop out of the educational system.

Key words: adolescents, situations of risk, Bedouins, educational systems, Negev 


\section{Introduction}

The formal educational system puts forth efforts to implement the education laws for all the children of Israel. Nevertheless, the system does not have an answer for the needs of some populations and does not allow these populations to realize themselves and their right to education. There are many factors that influence this situation, some are personal factors and some are factors related to the community or dependent on the educational system and the school. Education has a decisive role in the motivation of the individual towards integration and social advancement. The dropping out from the educational system is one of the main factors that perpetuates and preserves the social gaps that are encountered in every society and in Israel as well. ${ }^{1}$

The problem of dropping out is an acute problem with considerable significance in Arab society in general and in Bedouin society in particular. The research study examines the situation of the dropping out among adolescents in situations of risk in the Bedouin educational system in the $21^{\text {st }}$ century and examines the main problems, the reasons that lead them to drop out, while comparing between two types of villages, the recognized communities and the unrecognized communities. It is important to address the problem at its roots and to find ways and methods to reduce this phenomenon to the greatest possible extent. Hence, it is necessary to undertake intensive activity for the rehabilitation of these adolescents who have dropped out, to find the reasons for the dropping out, and to help the dropouts find educational frameworks that may suit them. In this way it will be possible to prevent or at least to reduce the phenomena that accompany dropping out, such as violence, crime, vagrancy, addictions to drugs, and so on. In recent years the local governments have begun to act on this matter but, in my opinion, this is not enough. The main reason (at least the declared reason) is that there are no budgets and today all the government offices are suffering from cuts. Reality proves that there is yet much to be done and that it is important to find solutions for the dropping out adolescents.

\section{The Bedouin Educational System}

The educational system in the Bedouin sector suffers from a wide variety of problems, including low achievements of the students, dropping out stu-

1S. Dovrat, The National Plan for Education: Report of the National Task Force for the Promotion of Education in Israel, Jerusalem 2005, p. 12. 
dents, lack of classes of study, deficiencies in the learning environment in the schools, lack of technological means, laboratories, and computers, lack of professional teaching workers and inadequate training of teaching workers, and disruption to the normal course of the studies because of tribal rivalries that penetrate in to the schools. ${ }^{2}$

According to the data of the Ministry of Education, in the 2016 school year a total of about 89,912 students from the Bedouin sector learn in the educational system (in the kindergartens and in the schools). The percentage of Bedouin students in the educational system is among the lowest in the country, at $5.4 \%$ of the entire population of students in the country. In the 2013 school year an average of 31 students studied in a class in the Bedouin sector, as opposed to an average of 26 students per class in the Jewish sector. In the past year, following the parent protest against the crowded classes, the Ministry of Education established a committee for the examination of this issue. The committee submitted its conclusions to the head of the Ministry of Education at the start of the year 2015. Following the committee's conclusions, there was a decline in the average number of students per class in the Bedouin sector. In the year 2016 the average number of students in the Bedouin sector was 27.8. Nevertheless, it is necessary to note that the number of students in the upper classes may greatly exceed the average, the level of education and achievements in the Bedouin educational system are lower, and frameworks of informal education barely exist. $60 \%$ of the Bedouin children in the Negev live under the poverty line. Only 15\% of three year old children and $43 \%$ of four year old children attend educational frameworks. $6.5 \%$ of the school students drop out during their studies, and those who dropped out do not have alternative frameworks of studies or professional training.

According to Amendment Number 16 of the Compulsory Education Law, 1984 children are entitled to compulsory education from the age of three. However, in the Bedouin sector the Ministry of Education does not arrange transportation for children of this age from considerations of budget and safety, and therefore in some of the unrecognized villages the children find it difficult to realize this right. According to the data of the Ministry of Education, in the academic year 2015 approximately 11,855 children aged three to five studied in the kindergartens in the Bedouin sector. The number of classes in the Bedouin communities in the school 2015 year was 502 kindergarten classes, for an average of about 23 children per class. These kindergartens can accept 16,275 children, but the use rate is only about $58 \%$. In

\footnotetext{
2 A. Haim, Letter, Manager of the Southern District, November 9, 2006, p. 77.
} 
addition, 57 kindergartens are now in stages of construction or planning, and they are intended for future acceptance of 1,995 children. Nevertheless, the data of the Ministry of Education indicates that today 4,434 children aged three and four in the Bedouin sector do not go to kindergarten.

The data of the Ministry of Education indicate that $65 \%$ of all children aged three and four who do not go to the kindergarten belong to the Alqasoum and Neve Midbar Councils. The Ministry of Education maintains that the main reason for the non-registration of children to the kindergartens is the great distance from the children's place of residence to the location of the kindergartens and the absence of transports to them. These are children who live in the unrecognized communities. These communities lack the infrastructures for the establishment of buildings and are not connected to water and electricity and are affiliated with the permanent communities.

The kindergartens in the unrecognized communities for the most part are found near the school structure and generally the schools share a yard with a number of kindergartens. According to a survey conducted by the Center for Research of Bedouin Society, in the year 2003, $80 \%$ of the kindergartens in the recognized communities and all the kindergartens in the unrecognized communities are housed in buildings that are not designated for this purpose, including trailer buildings and other temporary structures. Some of the prefabricated buildings are ancient, and the restrooms are outside of the classroom in a separate structure. Without a closet for cleaning materials, poisonous substances are stored where children can reach, and there is no separate room for a kitchen.

Surveys conducted by the Department for Environmental health of the Ministry of Health in the years 2005 and 2006 in the schools in the city of Rahat and in the unrecognized Bedouin villages found that the level of sanitation in most schools is very low. The picture delineated in these reports is of a very poor level of cleanliness in a large number of the schools. The classes are housed in temporary structures, most of which are old and not up to standard, and they are covered with carpets that accumulate dust and dirt. The restrooms in most of the schools are in a separate building in the yard. In $80 \%$ of the schools the level of cleanliness in the restrooms is abominable. There are no personal hygiene products (such as soap and toilet paper) and the structure of the restrooms is not acceptable. In the schools in the unrecognized communities some three hundred sinks and 260 toilets are absent. In the school yards there are not enough shaded areas. In some of the schools there is a lack of garbage cans, and the trash litters the yard. 
All the schools in the Bedouin sector, with the exception of those built in recent years, are prefabricated structures. Some are old and unsuited for studies. These schools are not connected to electricity infrastructures and the system of the roads. The supply of electricity to most of the schools is through a generator, and therefore it is impossible to operate air-conditioning units. Today, with the beginning of the activity of the Neve Midbar and Alqasoum Regional Councils the construction of schools in permanent buildings has commenced and they will be connected to infrastructures of electricity and transportation.

Many of the students in the Bedouin sector study in schools distant from their place of residence. In the elementary schools in Kuseife, Lakiya, and Segev Shalom more than $20 \%$ of the students live outside of the community. In the secondary schools in Kuseife and Segev Shalom more than $20 \%$ of the students live outside of the community. In the Neve Midbar and Alqasoum Regional Council there is a constellation of transportations of about 21,000 students every day, fully financed by the Ministry of Education. The studies in schools outside of the community of residence obligate the students to travel long distances to and from school, generally on dirt roads and substandard access roads. This situation creates a variety of problems, including the lack of possibility of coming to school because of road barriers in the winter and the risk of harm to the children who are transported to school.

In the schools in the Bedouin sector there is a real lack of positions in the auxiliary constellation - psychologists, educational counselors, and regular attendance officers. Because of the socioeconomic situation of the Bedouin communities and the special problems that the Bedouin public deals with, the needs of the Bedouin students in these fields are especially considerable. According to the desired standards, in the Arab sector in the Negev 49 positions of educational psychologists and 41.5 positions of regular attendance officers are needed. The Shatil Organization ${ }^{3}$, which concentrates the Arab education forum on the sector, presents data according to which in actuality only 14 positions have been allotted in educational counseling and 10 positions for regular attendance officers in the Bedouin sector. The schools in the Bedouin sector have been included in recent years in the five year plan for the promotion of the educational system and the reduction of gaps in the Bedouin sector in the South District. Through it the schools receive additional position hours and budgets for the purchase of equipment and the training of teaching workers is held. In addition, a number of additional

\footnotetext{
${ }^{3}$ Shatil is an acronym in Hebrew for Services of Support and Counseling for the Promotion of Social Change in Israel. In Hebrew the word means seedling.
} 
programs operate in them, such as the program for the prevention of dropping out, for the prevention of violence, and for children in situations of risk. ${ }^{4}$

The recognized Bedouin communities are not considered communities with national priority and the Karev Fund ${ }^{5}$ does not operate there. According to the Ministry of Education, in all the elementary schools in the recognized communities and in most of the elementary schools in the Abu-Basma Regional Council there is a long school day and food is provided in the school. However, according to conversations with the professionals who work in the field, the long school day and the food are provided only in a small number of the schools and at a very low level.

\section{Conservative Teaching Patterns}

The existing curricula and teaching patterns in the Bedouin educational system are conservative and hierarchical and do not cultivate in the students a feeling of self-worth and entitlement as citizens with equal rights in the determination of their future. The studies in the school are not directed to the development of independent thinking, the cultivation of initiatives that pertain to the individual and the collective, and the fulfillment of abilities of activity and self-help.

In addition, the Israeli educational system also shapes today a 'loyal' generation, dependent and submissive, in that it expropriates the identity and culture of the Arab child. Not only are the scholastic achievements in the Bedouin schools low but also the existing educational programs and curricula are not suited to the unique needs of Bedouin culture and society. In the Arab schools in the Negev the curricula are dictated by the Ministry of Education with barely any involvement of educators from the Bedouin Arab community in the Negev. The curricula lack contents and values that express Bedouin Arab culture, and they barely have reference to the Arab identity and the history to which the Arab child belongs. Instead there is an emphasis on the studies of the Jewish Bible, the history of the Jewish people, and Jewish tradition. The conflict that the educational system thus creates causes in the Bedouin Arab student frustration and confusion in all that per-

\footnotetext{
4 Shmid Program, 2006, p. 17.

${ }^{5}$ Karev Educational Program is a special framework for enrichment programs in the schools and kindergartens of the Ministry of Education with the goal of broadening the knowledge and skills among the students in addition to the formal programs.
} 
tain to the question of his identity and makes the gap between the generation of young people and the generation of the parents more extreme. In parallel, the system does not direct and does not instruct the counselors and psychologists to support the students and their family members.

For many years the Bedouin population has been immersed in the everyday struggle for physical existence and the efforts of the individual to survive in a changing world. More and more passiveness and less initiative are dominant in all that pertains to the life of the individual, the family, and the community, and patterns of behavior of 'defeat', 'inferiority', 'neediness', and 'hopelessness' have been created. In the population in general a profound identity crisis and personal and social frustration have been created, alongside alienation from Israeli society at large.

\section{Dropping the Settings}

According to the definitions of the Ministry of Education, Culture, and Sport (in the following: Ministry of Education), a drop out is a young person of compulsory education age (five to seventeen) who does not study in a school under the supervision of the Ministry of Education. Overt dropping out is the result of a continuous process, generally after a long period of covert dropping out (characterized by frequent absences, alienation towards the school, social rejection, violent behavior, and so on). ${ }^{6}$

Dropping out is defined as a phenomenon in which young people in Israel of the $21^{\text {st }}$ century do not succeed in acquiring a basic education and in finishing their studies and having formal or informal significant education that can help them in adulthood. Many research studies around the world7, which studied the phenomenon of the dropping out of students from schools, presented two main factors of dropping out: school factors related to the school system and environmental factors related to the family system and the community. Other research studies show that political factors influence the high percentage of dropping out among weak populations around the world. ${ }^{8}$

${ }^{6}$ Cohen-Navot et al., Research Report - The Overt and Covert Dropping out among Youths, Joint-Brookdale Institute, Knesset, Jerusalem 2001, p. 32.

7 J. Blackorby, I.J. Kortering, High School Dropout Students Identified with Behavioral Disorders, Behavioral Disorders, 1992, 18(1), p. 54; R.W. Rumberger, Dropping Out of High School: The Influence of Race Sex and Family Background, American Education Research Journal, 1983, 20(2), p. 16.

8 R.I. Colabres, J. Poe, Alienation: An Explanation of High School Dropout Rates among AfricanAmerican and Latino Students, Educational Research Quarterly, 1990, 14(4), p. 45. 


\section{Historical and Political Factors}

The Bedouin minority in the State of Israel has experienced many changes that have greatly influenced the situation of the Bedouin educational system. Abu-Saad (1995) divides Bedouin society into three main periods: the period before the State was established, the period of the establishment of the State, and the period of the end of the military government 1966 and the establishment of the new Bedouin communities (Tel Sheva, Kuseife, Hura, Ar'ara, Lakiya, Rahat, and Segev Shalom). The Bedouin educational system was characterized before the establishment of the State by an unofficial traditional educational system, without a defined scholastic program, and Bedouin society was not interested in learning things that were not relevant to their traditional lifestyle. In the period of the British Mandate, education in Bedouin society was in the kutab. The study classes were for the most part in the desert. The classes were very small and the access ways to the temporary schools were very difficult, distant from the roads and the places of residence. The students would make their way back and forth to the school by foot or by animal (donkey). In the $21^{\text {st }}$ century many of the students, both in the recognized communities and in the unrecognized communities, walk by foot to school, covering great distances and thus detrimentally influencing the quality of their learning.

\section{Dropping out of Adolescents in Risk Situations from the Bedouin Educational System}

In recent years, we encounter the steadily increasing use of the concept of 'youth at risk', which describes the population of youth who are found or who may be found in physical, mental, or emotional situations of risk. Over the last few years, there have been many attempts to describe, with different names, the population of youth who are at risk and are disconnected from the frameworks that society has designated for the age group in Israel. The population of disconnected youth represents the variety of groups and social strata in the State of Israel: native youths, youths who are the second and third generation in distress, immigrant youth, adolescents from the middle and upper class, Ultra-Orthodox youth, and youth from Arab society. ${ }^{9}$ The situations of crisis, risk, and danger derive from personal, family, social, and

9 Y. Friedman, A. Bandes Yakov, Outreach in the Service for Youths in the Ministry of Labor and Welfare, Jerusalem 2003, p. 23. 
socio-economic reasons and place the youths on the continuum of risk and danger, with functional problems in the educational system, covert and overt dropping out from the educational system, disconnection from the normative systems, and the crossing of red lines.

The dropping out of youths from the formal educational system is a phenomenon that accompanies the educational system in Israel and around the world. The rate of dropping out among children is estimated at 440 million children and youth (till age eighteen) who do not have any access to basic education and about 100 million children and youth who do not complete the basic studies and remain uneducated and illiterate. In Israel, there is considerable access to education, with the exception of the Bedouin sector, which does not live in recognized settlement. However, the phenomenon of dropping out exists and hundreds of youths do not complete an education. The data is encouraging: according to the Ministry of Education, in the past two decades there has been a significant reduction in the percentage of youths aged fourteen to seventeen who do not learn in the Jewish and Arab sectors.

Today the phenomenon of dropping out in Israel is concentrated primarily in secondary education in the age group of fifteen to seventeen. The overt and covert dropping out are dynamic phenomena developing over time and on the background of different variables that bring the youth to this situation. ${ }^{10}$ In addition, the dropping out of adolescents in situations of risk from the school is an active, gradual, and controllable process. The first stage is the result of the mistaken education that the children received in the family and the mistakes of teachers in the elementary school. The second stage is common in adolescence, when the adolescent begins to miss lessons and ignores accepted behavior norms. The third stage is characterized by a stable negative attitude towards the studies in the school. The adolescent is not interested in going to school, his scholastic achievements are low, and his behavior is aggressive. The fourth stage is the transition from covert dropping out to overt dropping out. ${ }^{11}$

Dolev, Kahan-Stravchinsky, and Shemesh ${ }^{12}$ report that Arab youths who have dropped out from educational frameworks are characterized by the fact that they come from very large families (more than four children, as

\footnotetext{
${ }^{10}$ Cohen-Navot et al., Research Report, p. 10.

${ }^{11} \mathrm{~K}$. Michael, Group Work with Parents and Adolescents Who Were Ejected from the Formal System of Studies, Reader and Review, 2000, 78, p. 67.

12 T. Dolev, P. Kahan-Stravchinsky, A. Shemesh, Survey of the Characteristics of Youths under the Care of the Units for Youth Promotion under the Supervision of the Ministry of Education - Research Report, Jerusalem 1999, p. 67.
} 
opposed to $17 \%$ among families in Israel), families where the parents have lower educational levels ( $77 \%$ of the fathers and $85 \%$ of the mothers) than Jewish youths (38\%), from families where the head of the household does not work, and from high residential crowding. Similarly, Gottleib and PoratBreinin $^{13}$ and Romi and Tal-Bar-Lev ${ }^{14}$ maintain that the family of disconnected youth is characterized by residence in disadvantaged neighborhoods and by affiliation to ethnic groups suffering from discrimination, which sometimes are a subculture and hold a system of values different from the normative system. The families have a poor social and economic background, and the percentage of families that are dysfunctional is high (because of illness, unemployment absence of parents, and so on). Children who grow up under these conditions experience cognitive, emotional, and social lacks, which eventually lead them to disconnection and delinquency.

The Bedouin population is found in general at risk, and adolescents in the Bedouin population are found at a very high level of risk. The drastic changes that Bedouin society in the Negev has experienced have created a vacuum in the social and community structure. Significant parts of the Bedouin identity, ceremonies and family, tribal, and social roles, have become less relevant. However, the adolescents at risk in Bedouin society are not equipped with the social-cultural mindset they need to take part in the industrial Western culture around them.

The educational system in the Bedouin sector is deficient, with poor achievements relative to the general population in Israel. In addition, $40 \%$ of the Bedouin adolescents drop out of the school by twelfth grade. While in the past these dropouts might have played an active part in the family tasks, such as shepherding and work in the fields, today these activities are less common and the lack of supervision of the behavior of children and youth have made them into a marginal population, needy and supported, found at the risk of the adoption of delinquent behaviors. 15 The research of Abu-Saad and Belmeker ${ }^{16}$ is a first study of the population of adolescents in the Bedouin population and the use of psychoactive substances, and it found that the use of substances among adolescents in the permanent communities is higher than that of adolescents in the Bedouin diaspora.

13 A. Gottleib, A. Porat-Breinin, Rehabilitation Programs for Disconnected Youths - Are They Effective? Jerusalem 1987, p. 12.

14 S. Romi, L. Tal-Bar-Lev, Religious Identity and Self Identity among Disconnected Youths and Normative Youths from an Ethiopian Origin, Society and Welfare, 2001, 21(1), p. 45.

${ }^{15} \mathrm{I}$. Abu-Saad, A. Belmeker, Survey of the Phenomenon of Use of Drugs among Bedouin Youths in the Negev: Trends and Recommendations, Beer Sheva 1998, p. 97.

${ }^{16}$ Ibidem, p. 98. 
Mizel17 in his research study maintained that the responsibility of the Bedouin schools in the presentation of scholastic achievements is not high. The research findings indicate that schools in Bedouin society lack educational responsibility associated with the traditional cultural responsibility that characterizes the Bedouin tribal sector. This responsibility in essence conflicts with the appointment of principals and teachers according to the political connections and social connections with role holders in the local governments and different role-holders in the government offices. These appointments, which for the most part are not professional, lead to poor academic outcomes in the Bedouin educational system. The research of Karnieli ${ }^{18}$ describes an intervention program in the schools in the Bedouin sector, in which the level of achievements is low and the percentage of dropping out is high among the students. A research study conducted by Ben David ${ }^{19}$ examined the scope of the dropping out in the Bedouin sector in the Negev. The research study focuses on the years 1986-1998 and included the population of students in the eleventh grades in the high schools in the Bedouin sector. The research results indicated a high percentage of voluntary dropping out and involuntary dropping out, higher than the parallel percentage among youths from the Jewish sector.

The Bedouin educational system in the State of Israel requires an intervention plan that characterizes the cultural values suited to it. Its goal is to create a new system of values, norms, and educational expertise that will lead to the increase of the scholastic achievements and will reduce the percentage of dropping out, which has been steadily declining in recent years. The intervention plan will be constructed on the basis of the anthropological perception, which will focus on the place and environment that can activate the person in his community, his identity, and general principles. Through the understanding about the culture and the school system, the program will prevent tensions among the teachers and school principals, as it knows the unique characteristics of the community and the educational system and generally will improve the scholastic achievements. It will promote the transition from centralized management to cooperative school management,

17 O. Mizel, Accountability in Arab Bedouin Schools in Israel: Accountable to Whom? Educational Management Administration \& Leadership, 2009, 37(5), p. 127.

${ }_{18}$ M. Karnieli, Invest in Your Children's Education the Way You Invest in Your Goats': Systemic Educational Intervention in a Traditional Bedouin Community - From Theory into Practice, Educational Action Research, 2000, 8(1). p. 13.

${ }^{19}$ Y. Ben David, Cultural and Environmental Factors that Influence the Dropping out of Students from the Secondary Schools in the Bedouin Sector in the Negev, Education Authority of the Bedouin, The Central Bureau of Statistics, Israel 2000, p. 55. 
transform the student from passive to active, improve the status of the school in the community, identify teachers who may become educational leaders, and preserve the cultural heritage and include it in the curriculum.

\section{Research Methods and Data Collection}

\section{Research Objective}

The research examines the tendency to drop out of adolescents in situations of risk in the recognized communities in comparison to adolescents at risk in the unrecognized communities regarding different demographic variables and the parents' involvement.

\section{Research Questions}

1. What are the main factors of the tendency of youths to drop out from the school?

2. Is there a relation between the socioeconomic status and the tendency to drop out from the school?

3. Is there a relation between the student's achievements and the tendency to drop out?

4. Are there differences in the place of residence in the dropping out?

5. Is there a relation between the involvement of the parents in the school and the tendency to drop out?

\section{Research Hypotheses}

1. As the social and economic situation is lower in the unrecognized community, the tendency to drop out from the school is higher among adolescents.

2. As the parents' education is lower, the tendency to drop out from the school is higher in the unrecognized community.

3. As the students' achievements in the school in the unrecognized community decline, the tendency to drop out is higher.

4. The tendency to drop out among adolescents in situations of risk in the unrecognized community is higher than that of adolescents in situations of risk in the recognized community.

5. As the parents are less involved in the school in the unrecognized community, adolescents in situations of risk tend more to drop out from the school. 


\section{Research Population}

The sample consisted of 90 adolescents in situations of risk, 45 adolescents from recognized communities and 45 adolescents from unrecognized communities. The method of selection of the respondents was purposive sampling, to include as much as possible geographic distribution of respondents in the recognized communities and unrecognized communities in the Negev.

\section{Research Instruments}

The research study employed a questionnaire that examined a number of aspects: demographic data about the respondents, tendency to drop out (school climate, social climate, teacher-student relations), and parents' involvement.

1. The demographic information questionnaire. The purpose is to provide information about the personal background of every respondent, which includes demographic information, such as age, sex, and socioeconomic status.

2. Tendency to drop out. The questionnaire is composed of seventeen questions on the topic of the student's involvement in the school, social climate, and teacher-student relations.

3. Parents' involvement. The purpose is to examine the degree to which the parents are involved in what is done in the school. There are six items in the questionnaire.

\section{Research Findings}

The research study presents initial and unique findings that include authentic evidence from which it is possible to learn about the approaches of teachers and educators to different research studies and especially about the phenomenon of dropping out of adolescents at risk in the Bedouin sector, in the comparison between recognized communities and unrecognized communities. The research findings indicate that there is a tremendous gap in the knowledge that educators hold, between their attitude and outlook and the social and cultural conflict that is contradictory to the issue of social integration and the regular school studies in the Bedouin sector. In the past decade there are many gaps between the interaction of the educational staff of schools in the Bedouin population and Bedouin society (the parents), who see themselves as an empowering part in the school system, in contrast to 
the school principals, who object strongly to their involvement in the learning process.

Tendency to drop out. This variable is the mean of three dimensions, non-involvement in what is done in the school, negative relations between the teacher and his students, and a shaky climate between adolescents at risk in the school. The mean of the variable of tendency to drop out was calculated, $2.84(0.50)$. This mean characterizes a moderate tendency to drop out of the students from the school. The mean of the dimension of negative relations between the teacher and the student was calculated and is dominant, 3.18 (0.87).

Parent involvement. The mean of the variable of parent involvement was calculated, $3.20(0.92)$. This mean is moderate and indicates a moderate degree of involvement of the students' parents in what is done in the school.

The following table presents the indices of center and dispersion of the research variables.

\begin{tabular}{|l|c|c|c|c|c|c|}
\hline \multicolumn{1}{|c|}{ Research Variables } & Scale & $\mathrm{N}$ & Min & Max & Mean & SD \\
\hline Tendency to drop out & $1-5$ & 40 & 1.35 & 4.12 & 2.84 & 0.50 \\
\hline Student involvement in the school & $1-5$ & 40 & 1.60 & 3.90 & 2.69 & 0.56 \\
\hline Teacher-student relations & $1-5$ & 40 & 1.00 & 5.00 & 3.18 & 0.87 \\
\hline Social climate & $1-5$ & 40 & 1.00 & 4.67 & 2.91 & 0.75 \\
\hline Parent involvement & $1-5$ & 40 & 1.17 & 5.00 & 3.20 & 0.92 \\
\hline
\end{tabular}

\section{Inferential Statistics - Examination of the Research Hypotheses}

Hypothesis Number 1. As the social and economic situation is lower in the unrecognized community, the tendency to drop out from the school is higher among adolescents at risk in the school.

To examine the hypothesis, the Pearson test was conducted between the variables. Table 2 presents the test findings. 


\begin{tabular}{|l|c|c|c|}
\hline \multicolumn{1}{|c|}{ Variable } & Variable & Sig & $\mathrm{R}$ \\
\hline Tendency to drop out & \multirow{4}{*}{ Social Status } & 0.13 & -0.24 \\
\hline Student involvement in the school & & 0.21 & -0.20 \\
\hline Teacher-student relations & & 0.36 & -0.15 \\
\hline Social climate & & 0.29 & -0.17 \\
\hline
\end{tabular}

The table shows that, in contrast to the hypothesis, a significant relation was not found between the adolescent's economic/social status and the tendency to drop out, $\mathrm{r}=-0.24, \mathrm{p}>0.05$. In addition, a significant relation was not found between the perception of the social/economic status and the involvement of the adolescent in the school the degree of the relations with the teachers and the social climate. Thus, hypothesis number 1 was refuted.

Hypothesis Number 2. As the parents' education is lower, the tendency to drop out from the school is higher in the unrecognized community.

To examine this hypothesis, Pearson test between the variables was conducted. Table 3 presents the findings.

\begin{tabular}{|l|c|c|c|}
\hline \multicolumn{1}{|c|}{ Variable } & Variable & sig & $\mathrm{R}$ \\
\hline Father education & \multirow{2}{*}{ Tendency to drop out } & 0.21 & -0.20 \\
\cline { 3 - 4 } Mother education & & 0.36 & -0.15 \\
\hline
\end{tabular}

The table shows that, in contrast to our hypothesis, a significant relation was not found between the parents' education and the tendency of the adolescent to drop out, $\mathrm{r}=-0.20, \mathrm{p}>0.05$. Thus, hypothesis number 2 was refuted.

Hypothesis Number 3. As the students' achievements in the school in the unrecognized community are lower, the tendency to drop out is higher.

To examine the hypothesis, Pearson test between the variables was performed. Table 4 presents the test findings.

\begin{tabular}{|l|c|c|c|}
\hline \multicolumn{1}{|c|}{ Variable } & Variable & sig & $\mathrm{R}$ \\
\hline Tendency to drop out & & 0.77 & -0.05 \\
\cline { 1 - 1 } Student involvement in the school & \multirow{3}{*}{ Scholastic achievements } & 0.59 & -0.09 \\
\cline { 1 - 2 } Teacher-student relations & & 0.79 & -0.04 \\
\cline { 1 - 1 } Social climate & & 0.51 & 0.11 \\
\hline
\end{tabular}

The table shows that, in contrast to the hypothesis, a significant relation was not found between the student's scholastic achievements and the ten- 
dency to drop out, $r=-005, p>0.05$. In addition, a significant relation was not found between the achievements and the adolescent's involvement in the school, degree of relations with the teachers, and social climate. Thus, hypothesis number 3 was refuted.

Hypothesis Number 4. The tendency to drop out among adolescents in situations of risk in the unrecognized community is higher than that of adolescents in situations of risk in the recognized community.

To examine this hypothesis, t-test for independent samples was performed. Table 5 presents the findings of the test.

\begin{tabular}{|c|c|c|c|c|c|c|}
\hline Variable & Residence Place & $\mathrm{N}$ & Mean & SD & Sig & $\begin{array}{c}\mathrm{T} \\
\text { test }\end{array}$ \\
\hline \multirow[b]{2}{*}{$\begin{array}{l}\text { Dropping } \\
\text { out }\end{array}$} & $\begin{array}{l}\text { Adolescents, recognized } \\
\text { community }\end{array}$ & 14 & 2.71 & 0.58 & \multirow[b]{2}{*}{0.21} & \multirow[b]{2}{*}{1.25} \\
\hline & $\begin{array}{l}\text { Adolescents, unrecognized } \\
\text { community }\end{array}$ & 26 & 2.92 & 0.45 & & \\
\hline
\end{tabular}

The table shows that in contrast to the hypothesis differences between adolescents in situations of risk were not found in the degree of the perception of the tendency to drop out, $\mathrm{t}=1.25, \mathrm{p}>0.0 .5$. Therefore, hypothesis number 4 was refuted.

Hypothesis Number 5. As the parents are less involved in the school in the unrecognized community, adolescents tend more to drop out from the school.

To examine this hypothesis, Pearson test between the variables was performed. Table 6 presents the findings.

\begin{tabular}{|c|c|c|c|}
\hline Variable & Variable & $\operatorname{sig}$ & $\mathrm{R}$ \\
\hline Tendency to drop out & \multirow{4}{*}{ Parent involvement } & 0.002 & $-0.48 * *$ \\
\hline $\begin{array}{l}\text { Student involvement in the } \\
\text { school }\end{array}$ & & 0.00 & $-0.53 * *$ \\
\hline Teacher-students relations & & 0.36 & -0.15 \\
\hline Social climate & & 0.10 & 0.26 \\
\hline
\end{tabular}

The table shows that according to the hypothesis, a significant negative relationship of moderate intensity was found between the degree of in- 
volvement of the parents in what is done in the school and the tendency to drop out, $\mathrm{r}=-0.48, \mathrm{p}<0.01$. In addition, a significant negative relation was found between the parents' involvement and adolescents' involvement in the school. Thus, it is possible to conclude that, as the parents are less involved in the school, the adolescents tend more to drop out from the school. Therefore, hypothesis number 5 was confirmed.

\section{Discussion and Conclusions}

The Bedouin educational system is a system that suffers from many problems, when $22 \%$ of all the students in Israel learn in the Bedouin educational system, which is characterized by the poor quality of the schools, by overcrowding in the classes, by a lack of teachers and staff, by deficient construction and maintenance, by geographic distance, and by the lack of libraries, computers, and laboratories. There is a considerable degree of difference and inequality in the resources allotted to education in the Arab sector as opposed to the Jewish sector. These differences are reflected in different components of the educational system in the Bedouin sector, such as physical infrastructures, average number of children in the class, number of enrichment hours, scope of the support services, and level of education of the professional staff. Nevertheless and despite the establishment of the committees for the reduction of the gap and despite the many associations that act to achieve equality of rights for the Bedouin minority, the gap still exists. The gap also pertains to the problem of the dropping out from which the Bedouin sector suffers, and therefore the present work examined the tendency to drop out among adolescents in the Bedouin/ Arab sector.

Examination of the descriptive statistics indicates that the variable of tendency to drop out has a moderate value, thus indicating a moderate tendency towards dropping out of adolescents from the school. Examination of the parents' involvement also found a moderate score that indicates a moderate degree of involvement of parents of adolescents in what is done in the school. These data are surprising in light of the review of the articles that address the topic. The research studies about Bedouin education indicate a low involvement of the parents and an especially high rate of dropping out. Hence, the scores obtained for the dropping out and for the involvement are surprising and perhaps hint at a possible change of approach to the future.

The examination of the inferential statistics included reference to the five research hypotheses, when the first hypothesis maintained that as the eco- 
nomic and social situation is lower in an unrecognized community, the tendency to drop out among adolescents in situations of risk in the school is greater. The findings of the Pearson test showed that a significant relation was not found between the social and economic status of the student and the tendency to drop out. In addition a significant relation was not found between the perception of the social and economic status and the adolescent's involvement in the school, degree of relations with the teachers, and the social climate. Thus, hypothesis number 1 was refuted. These findings contradict the literature to a certain degree, since according to the research study of Cohen-Navot, Allenbogen-Frankovitz, and Reinfeld ${ }^{20}$, youths who belong to poor families have a high chance of dropping out from the school.

The second hypothesis maintained that as the education of the parents is lower in the unrecognized community, the tendency to drop out is higher. The findings of the Pearson test showed that a significant relation was not found between the education of the student's parents and the tendency to drop out. Thus, hypothesis number 2 was refuted.

These findings contradict the research literature. According to AbuSaad $^{21}$, the fact that the parents did not experience formal studies, do not know the structure of the educational system, are not aware of their children's rights in it, and do not know ways of active and constructive involvement in the process of their education leads to a reality in which the parent is not involved in the formal educational process of his children and the child can reach the point of dropping out from the system.

The third hypothesis maintained that as the adolescent's achievements in the school in the unrecognized community declines, the tendency to drop out is higher. The Pearson test findings showed that a significant relation was not found between the adolescent's scholastic achievements and the tendency to drop out. In addition, a significant relation was not found between the degree of achievements and the adolescent's involvement in what is done in the school, degree of the relations with the teachers, and the social climate. Thus, hypothesis number 3 was refuted.

These findings contradict the literature, which maintains that for the most part students with low achievements are the population that drops out; in other words, the absence of skills and learning habits, poor scholastic achievements, presence in programs, tracks, or low frameworks, and poor

${ }^{20}$ Cohen-Navot et al., Research Report, p. 45.

${ }^{21}$ A. Abu Saad, Multicultural Education and the Palestinian Arab minority in Israel: The issue of education in the Negev Arab-Bedouin, [in:] Education in a Multicultural Society: pluralism and a meeting point between cultural rifts, ed. P. Perry, Tel Aviv 2007, p.134. 
motivation in the studies lead for the most part to dropping out and transitions between frameworks. ${ }^{22}$

The fourth hypothesis maintained that the tendency to drop out among adolescents in situations of risk in an unrecognized community is higher than that of adolescents in situations of risk in a recognized community. Pearson test findings showed that differences do not exist between adolescents in situations of risk in the degree of the perception of the tendency to drop out. Hypothesis number 4 was refuted.

These findings are not commensurate with the research literature, when Faisal (2007p.88) maintains that adolescents in situations of risk drop out more than do normative adolescents and that one of the reasons is the use of addictive substances that lead adolescents in general and the Arab adolescent in particular to leave the educational system.

The fifth and last hypothesis maintained that as the parents are less involved in the school in the unrecognized community the adolescents tend more to drop out from the school. The findings of the Pearson test showed that there is a significant negative relation of moderate intensity between the degree of involvement of the parents in what is done in the school and the tendency to drop out. In addition, a negative significant relation was found between the degree of involvement of the parents and the involvement of the student in what is done in the school. Therefore, it is possible to conclude that as the parents are less involved in the school, the adolescents tend more to drop out from the school and the reverse holds true. These findings confirm the fifth hypothesis.

These findings are commensurate with the literature, which holds that the involvement of the parents in the school life influences in favor of the motivation to learn and the desire of the adolescents to acquire an education and the ability of the family to influence the dropping out of the adolescents from the school. 23

Examination of the research findings indicates that the parents' involvement influences the dropping out significantly while the rest of the hypotheses were refuted. This finding indicates the importance of the parents' involvement in the school and its importance for the children's future. In other words, a Bedouin child with an involved family has greater likelihood of remaining in the educational framework. However, a Bedouin child whose parents are disconnected from his studies has increased chances to drop out from the educational system.

${ }^{22}$ Cohen-Navot et al., Research Report, p. 77.

${ }^{23}$ K. Michael, Group Work with Parents and Adolescents, p. 13. 
While the research hypotheses were refuted, from my familiarity with the Bedouin sector I know that dropping out exists and that this phenomenon is worsening. Indeed, the research literature holds that the fact that the society is a traditional society presents a different approach towards education, to differentiate from the approach in Israeli society. The difference lies in the fact that education is not viewed as essential in Bedouin society; education and enlightenment in general are not important, since it is far more important to help the livelihood of the family and the daughters are married already at a young age. In addition, most of the mothers are illiterate and do not believe in their ability to help in the formal education of their children. They are also not permitted, according to tradition, to come to the schools, which are distant from their residences, and to create relationship with the teachers, most of whom are men. The staffs of teachers, on their part, do not encourage relationships with the parents. Consequently, the public of parents is not aware of the needs of the child related to his education in the scholastic frameworks.

To conclude, the phenomenon of dropping out is, according to the research literature, severe. There is dropping out from the school, there is awareness of the dropping out, but there is less awareness of its severe implications. Moreover, it does not appear that the Bedouin population is undertaking actions to halt the phenomenon. Therefore, it is without a doubt necessary to provide an immediate solution that will lead to the end of the dropping out, for the future of the children of the Bedouin sector.

\section{BIBLIOGRAPHY}

Abu Saad A., Multicultural Education and the Palestinian Arab minority in Israel: The issue of education in the Negev Arab-Bedouin, [in:] Education in a Multicultural Society: pluralism and a meeting point between cultural rifts, ed. P. Perry, Carmel, Tel Aviv 2007.

Abu-Saad I., Bedouin Arabs' Education in the Control vs. Development among Indigenous Peoples: The Case of Bedouin Arabs in Israel, HAGAR - International Social Science Review, 1995, 2(2).

Abu-Saad I., Belmeker A., Survey of the Phenomenon of Use of Drugs among Bedouin Youths in the Negev: Trends and Recommendations, The Center for Research of Bedouin Society and Its Development, Beer Sheva 1998 (Hebrew).

Ben David Y., Cultural and Environmental Factors that Influence the Dropping out of Students from the Secondary Schools in the Bedouin Sector in the Negev, Education Authority of the Bedouin, Ministry of Education and the Van Lear Institute for the Research of Israel, The Central Bureau of Statistics, 2000 (Hebrew).

Blackorby J., Kortering I.J., High School Dropout Students Identified with Behavioral Disorders, Behavioral Disorders, 1992, 18(1). 
Cohen-Navot et al., Research Report - The Overt and Covert Dropping out among Youths, Joint-Brookdale Institute, Center for Information, Israel, Knesset, Jerusalem 2001 (Hebrew).

Colabres R.I., Poe J., Alienation: An Explanation of High School Dropout Rates among AfricanAmerican and Latino Students, Educational Research Quarterly, 1990, 14(4).

Dolev T., Kahan-Stravchinsky P., Shemesh A., Survey of the Characteristics of Youths under the Care of the Units for Youth Promotion under the Supervision of the Ministry of Education - Research Report, Joint-Brookdale Insittute, Jerusalem 1999 (Hebrew).

Dovrat S., The National Plan for Education: Report of the National Task Force for the Promotion of Education in Israel, Ministry of Education, Culture, and Sport, Jerusalem 2005 (Hebrew).

Faisal E., The Use of Psychoactive Substances among Adolescents from the Arab Population of Israel that Dropped out of the Studies, Encounter for Social Educational Work, 2007, 26. (Hebrew)

Friedman Y., Bandes Yakov A., Outreach in the Service for Youths in the Ministry of Labor and Welfare, Ministry of Labor and Welfare, The Service for Youths, the Henrietta Szold Institute, Jerusalem 2003 (Hebrew).

Gottleib A., Porat-Breinin A., Rehabilitation Programs for Disconnected Youths - Are They Effective? The Institute for the Research of Cultivation in Education, Jerusalem 1987 (Hebrew).

Haim A., Letter, Manager of the Southern District, Ministry of Education, November 9, 2006 (Hebrew).

Horowitz T., Persevering, Mobile, and Dropping out - the Individual and the System in the Secondary School, Research Report 224 (Publication Number 616), The Henrietta Szold Institute, The National Institute for Research in the Behavioral Sciences, Jerusalem 1984 (Hebrew).

Karnieli M., Invest in Your Children's Education the Way You Invest in Your Goats': Systemic Educational Intervention in a Traditional Bedouin Community - From Theory into Practice, Educational Action Research, 2000, 8(1).

Michael K., Group Work with Parents and Adolescents Who Were Ejected from the Formal System of Studies, Reader and Review, 2000, 78 (Hebrew).

Mizel O., Accountability in Arab Bedouin Schools in Israel: Accountable to Whom? Educational Management Administration \& Leadership, 2009, 37(5).

Romi S., Tal-Bar-Lev L., Religious Identity and Self Identity among Disconnected Youths and Normative Youths from an Ethiopian Origin, Society and Welfare, 2001, 21(1) (Hebrew).

Rumberger R.W., Dropping Out of High School: The Influence of Race Sex and Family Background, American Education Research Journal, 1983, 20(2).

Shmid H., Report of the Public Committee for the Examination of the Situation of Children and Youths at Risk and in Distress, The State of Israel, Jerusalem 2006 (Hebrew).

Weizman S., Friedman R., Ejection from School - a Conceptual Approach to the Review of the Literature, Trends, 1994, 37(2) (Hebrew). 
